\title{
Long-chain fatty acid uptake is upregulated in omental adipocytes from patients undergoing bariatric surgery for obesity
}

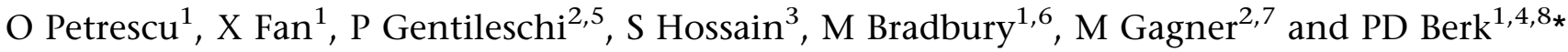 \\ ${ }^{1}$ Department of Medicine (Division of Liver Disease), Mount Sinai School of Medicine, New York, NY, USA; ${ }^{2}$ Department \\ of Surgery, Mount Sinai School of Medicine, New York, NY, USA; ${ }^{3}$ Department of Biomathematics, Mount Sinai School of \\ Medicine, New York, NY, USA; and ${ }^{4}$ Department of Cell, Molecular, and Developmental Biology, Mount Sinai School of \\ Medicine, New York, NY, USA
}

OBJECTIVE: To determine the impact of obesity on adipocyte cell size and long-chain fatty acid (LCFA) uptake kinetics in human subjects undergoing laparoscopic abdominal surgery.

SUBJECTS: A total of 10 obese patients (BMI $49.8 \pm 11.9$ (s.d.) $\mathrm{kg} / \mathrm{m}^{2}$ ) undergoing laparoscopic bariatric surgery, and 10 nonobese subjects (BMI $24.2 \pm 2.3 \mathrm{~kg} / \mathrm{m}^{2}$ ) undergoing other clinically indicated laparoscopic abdominal surgical procedures.

MEASUREMENTS: Cell size distribution and $\left[{ }^{3} \mathrm{H}\right]$ oleic acid uptake kinetics were studied in adipocytes isolated from omental fat biopsies obtained during surgery. Adipocyte surface area $(S A)$ was calculated from the measured cell diameters. Plasma leptin and insulin concentrations were measured by RIA in fasting blood samples obtained on the morning of surgery.

RESULTS: The mean SA of obese adipocytes $\left(41508 \pm 5381 \mu^{2} /\right.$ cell) was increased 2.4-fold compared to that of nonobese adipocytes $\left(16928 \pm 6529 \mu^{2} /\right.$ cell; $\left.P<0.01\right)$. LCFA uptake in each group was the sum of saturable and nonsaturable components. Both the $V_{\max }$ of the saturable component $(21.3 \pm 6.3 \mathrm{vs} 5.1 \pm 1.9 \mathrm{pmol} / \mathrm{s} / 50000$ cells) and the rate constant $k$ of the nonsaturable component $(0.015 \pm 0.002$ vs $0.0066 \pm 0.0023 \mathrm{ml} / \mathrm{s} / 50000$ cells $)$ were increased $(P<0.001)$ in obese adipocytes compared with nonobese controls. When expressed relative to cell size, $V_{\max } / \mu^{2}$ SA was greater in obese than nonobese adipocytes $(P<0.05)$, whereas $k / \mu^{2}$ SA did not differ between the groups.

CONCLUSION: The data support the concepts that (1) adipocyte LCFA uptake consists of distinct facilitated (saturable) and diffusive processes; (2) increased saturable LCFA uptake in obese adipocytes is not simply a consequence of increased cell size, but rather reflects upregulation of a facilitated transport process; and (3) the permeability of adipocyte plasma membranes to LCFA is not appreciably altered by obesity, and increased nonsaturable uptake in obese adipocytes principally reflects an increase in cell SA. Regulation of saturable LCFA uptake by adipocytes may be an important control point for body adiposity.

International Journal of Obesity (2005) 29, 196-203. doi:10.1038/sj.ijo.0802868

Published online 30 November 2004

Keywords: facilitated transport; insulin; leptin; nutrient partitioning; diffusion

*Correspondence: Dr PD Berk, Columbia Presbyterian Medical Center, Division of Digestive and Liver Diseases, Box 83, BB 912, 630 West 168th Street, New York, NY 10032, USA.

E-mail: pb2158@columbia.edu

${ }^{5}$ Current address: Department of Surgery, University of Tor Vergata, Rome, Italy.

${ }^{6}$ Current address: Lake Erie College of Osteopathic Medicine, Erie, PA 16505, USA.

${ }^{7}$ Current address: Department of Surgery (Division of Laparoscopic Surgery), Weill Medical College of Cornell University, New York, NY 10021, USA.

${ }^{8}$ Current address: Department of Medicine (Division of Digestive and Liver Diseases), Columbia Presbyterian Medical Center, New York, NY 10032, USA.

Received 19 March 2004; revised 29 September 2004; accepted 30 September 2004; published online 30 November 2004

\section{Introduction}

Obesity is, virtually by definition, the excessive retention and storage of long-chain fatty acids (LCFA), principally as triglycerides, in adipose and other tissues. Nevertheless, although certain aspects of LCFA disposition, and intermediary metabolism in general, have been widely studied in obese patients and in related animal models of obesity, there have been few studies of the trans-plasma membrane transport and consequent cellular uptake of LCFA in these settings, and none, to our knowledge, in human subjects.

Although cellular LCFA uptake was long considered to be an entirely passive, unregulated process, we and others have established that LCFA enter cells such as adipocytes by two distinct pathways: saturable, and presumably protein- 
mediated transport of LCFA anions and passive 'flip-flop' of protonated LCFA. ${ }^{1,2}$ We have also shown that obesity resulting from a variety of causes (eg genetic, dietary) in several rodent species is associated with the tissue-specific upregulation of saturable LCFA uptake by adipocytes, but not by hepatocytes or cardiac myocytes. ${ }^{3,4}$ These findings suggest (1) that the selective upregulation of adipocyte LCFA uptake in obesity alters LCFA partitioning, diverting LCFA away from tissues where they would be consumed as fuel to adipose tissue, where they are stored as triglycerides; and (2) that the increase in saturable LCFA uptake reflects upregulation of specific membrane transport process(es). In animal models such as the $o b / o b$ mouse, insulin appears to be an important upregulator and leptin a key downregulator of adipocyte LCFA uptake. ${ }^{5}$ The observation that, in particular experimental settings, upregulation of adipocyte LCFA uptake precedes weight gain, ${ }^{3}$ whereas downregulation of adipocyte LCFA uptake precedes weight $\operatorname{loss}^{5}$ further suggests that regulation of saturable LCFA uptake may be an important control point for body adiposity. ${ }^{6}$

We here describe studies of the uptake kinetics of 9,10$\left[{ }^{3} \mathrm{H}\right]$ oleic acid (OA) by omental adipocytes isolated from obese patients undergoing laparoscopic bariatric surgical procedures, and compare the results with those obtained with omental adipocytes isolated from nonobese individuals undergoing a variety of other, clinically indicated laparoscopic procedures. Although it was not possible to obtain samples of liver and cardiac muscle for studies of LCFA uptake in these patients, the upregulation of adipocyte LCFA uptake observed in the obese subjects suggests that in human as well as rodent obesity, alterations in LCFA partitioning that favor storage over metabolism contribute to the obese phenotype.

\section{Methods \\ Patients}

The study population consisted of 20 patients undergoing clinically indicated abdominal laparoscopic surgical procedures, who consented to removal of an omental fat sample during surgery for studies of LCFA transport and a venous blood sample for the measurement of plasma levels of insulin and leptin. A total of 10 of the patients (five males, five females) were obese, and were undergoing bariatric surgical procedures related to their obesity. Four of them (two males, two females) had elevated fasting blood glucose concentrations. These ranged from 141 to $170 \mathrm{mg} / \mathrm{dl}$ at operation, but none was on medications likely to influence glucose or fatty acid metabolism for at least 2 weeks prior to surgery. The other 10 patients (five males, five females) were nonobese, and were undergoing a variety of clinically indicated laparoscopic procedures, including donor nephrectomy (4), cholecystectomy (2), inguinal hernia repair (1), removal of a mucinous cystadenoma (1), relief of celiac compression (1), and repair of a hiatal hernia for relief of symptoms of gastroesophageal reflux disease (GERD) (1). None was diabetic, had a significant chronic inflammatory disease or malignancy, or was on medications likely to influence glucose or fatty acid metabolism at the time of surgery. The protocol and consent documents and procedures for these studies were approved by the Institutional Review Board (IRB) of the Mount Sinai School of Medicine.

\section{Materials}

OA was purchased from NEN Life Science Products (Boston, MA, USA), type I collagenase for adipocyte isolation from Sigma (St Louis, MO, USA), fatty acid-free bovine serum albumin (BSA) from Boehringer Mannheim (Indianapolis, IN), and human insulin-specific- and leptin-specific RIA kits from Linco Research, Inc. (St Charles, MO, USA).

\section{Preparation of isolated adipocytes}

Single cell suspensions of human adipocytes were prepared from the omental fat samples by collagenase digestion, as previously described..$^{7-9}$ All preparations used in subsequent studies met established viability criteria. ${ }^{9}$ Optimal viability was achieved by maintaining the cells at room temperature in Dulbecco's modified Eagle's medium (DMEM) after isolation, and rewarming them to $37^{\circ} \mathrm{C}$ just prior to use. The distribution of cell diameters in each preparation was determined by direct microscopy at $\times 100$, using a graduated eyepiece reticle with which measurements of cell diameter were recorded in arbitrary units (U). After conversion to micrometers $(\mu)(1 \mathrm{U}=9.6 \mu \mathrm{m})$, the corresponding mean cell surface area (SA), in $\mu^{2}$, was calculated. ${ }^{10}$

\section{LCFA uptake studies}

Cell aliquots from each preparation were incubated at $37^{\circ} \mathrm{C}$ in DMEM containing $500 \mu \mathrm{M}$ BSA $^{11,12}$ and one of five different concentrations of OA, such that the OA:BSA molar ratio $(v)$ was $0.25,0.5,1.0,1.5$, or $2.0: 1$. The initial velocity $\left(V_{0}\right)$ of cellular oleate uptake from each test solution was determined by a standard, rapid filtration technique ${ }^{7-9,13}$ from four samples obtained in triplicate over the initial $30 \mathrm{~s}$ of incubation, during which uptake was a linear function of time.

\section{Computations and data fitting}

The unbound oleate concentration $\left(\left[\mathrm{OA}_{\mathrm{u}}\right]\right)$ in each test solution was calculated from $v{ }^{14}$ using the LCFA:BSA binding constants of Spector et al ${ }^{15}$ Our rationale for the use of these particular binding constants rather than several alternative, more recently determined values ${ }^{16-18}$ has been reported in detail previously. ${ }^{5}$

Based on prior analyses, ${ }^{2}$ measurements of initial oleate uptake velocity at values of $v$ from 0.25 to 2.0 were fitted to the sum of a saturable and a nonsaturable function of the 
corresponding $\left[\mathrm{OA}_{\mathrm{u}}\right]$, according to the equation:

$$
\mathrm{UT}\left(\left[\mathrm{OA}_{\mathrm{u}}\right]\right)=\left(V_{\max }\left[\mathrm{OA}_{\mathrm{u}}\right]\right) /\left(K_{\mathrm{m}}+\left[\mathrm{OA}_{\mathrm{u}}\right]\right)+\mathrm{k}\left[\mathrm{OA}_{\mathrm{u}}\right] \text {, }
$$

in which $\mathrm{UT}\left(\left[\mathrm{OA}_{\mathrm{u}}\right]\right)$ is the experimental measurement of uptake, in $\mathrm{pmol} / \mathrm{s} / 50000$ cells, at the stipulated concentration of unbound oleic acid; $V_{\max }$ and $K_{\mathrm{m}}$ are, respectively, the maximal uptake velocity of the saturable oleic acid uptake component and the value of $\left[\mathrm{OA}_{\mathrm{u}}\right]$ at one-half the maximal uptake velocity; and $k$ is the rate constant for nonsaturable uptake. $^{1-5,9}$ Data fitting was accomplished using the SAAM II version of the Simulation, Analysis and Modeling (SAAM) program of Berman and Weiss ${ }^{19}$ as modified for execution on a lap-top PC computer. ${ }^{20}$ SAAM uses an iterative, nonlinear algorithm to compute for each data set values of the $V_{\max }$ (pmol/s/50000 cells) and $K_{\mathrm{m}}(\mathrm{nM})$ of the saturable uptake function, and the rate constant $k(\mathrm{ml} / \mathrm{s} / 50000$ cells) for the nonsaturable uptake process, as well as their variances and covariances. Prior studies in isolated hepatocytes and adipocytes have documented that, when measured under the specific conditions employed in the current studies, $V_{0}$ and derived parameters such as $V_{\max }$ are measures of transmembrane transport. Their values are largely unmodified by such premembrane phenomena as rate-limiting dissociation from albumin and the effects of the pericellular unstirred water layer on substrate availability at the cell surface, or of subsequent intracellular binding or metabolism. ${ }^{11-13}$ Further studies, in which an increase in $V_{\max }$ was shown to precede an increase in adipocyte size early in the development of obesity, ${ }^{3}$ and a decrease in $V_{\max }$ preceded a reduction in adipocyte size during leptin-induced weight $\operatorname{loss}^{5}$ clearly established that changes in $V_{\max }$ did not reflect changes in cell volume.

\section{Statistical considerations}

Values for physiologic variables are reported as mean \pm s.d., calculated according to standard methods of descriptive statistics. $^{21}$ The significance of obesity and gender were tested in two-way factorial ANOVAs, using a log transformation to accommodate disparate variances where needed.

\section{Results}

\section{Patients}

Overall, the obese and nonobese patient groups were similar in age (Table 1). By definition, the obese patients weighed more and had significantly higher BMIs $(P<0.001)$. Plasma insulin $(P=0.016)$, leptin $(P<0.001)$, and glucose $(P<0.001)$ concentrations were also significantly higher in the obese patient group, but small increases in cholesterol and triglycerides did not achieve statistical significance.

\section{Adipocytes}

Within each isolated adipocyte preparation, the distribution of cell diameters was not Gaussian, but rather skewed to the right, due to the presence of a small subpopulation of very large cells. For this reason, the mean SA per cell within each preparation was calculated from the formula of Di Giralomo et $a l^{10}{ }^{10}$ rather than that of Zinder and Shapiro, ${ }^{22}$ since the former more accurately reflects the disproportionate contribution to the total SA of the population derived from these very large cells. At $41508 \pm 5381 \mu^{2} /$ cell, the mean SA of adipocytes from obese patients was 2.4 -fold greater than that of adipocytes from nonobese subjects $\left(16928 \pm 6529 \mu^{2} /\right.$ cell $)$ (Table 2; $P<0.01$ ).

\section{LCFA uptake studies}

Representative OA uptake studies in adipocyte suspensions from one obese and one nonobese subject are illustrated in Figure 1. Data points are depicted as the mean \pm s.d. of triplicate determinations. Each curve clearly consists of distinct saturable and nonsaturable components, and represents a computer fit of the data to Eq (1). Total uptake, as well as each of its components, is appreciably faster in the obese than in the nonobese cells. Computer-fitted curves in all studied individuals are shown in Figure 2. Uptake in all of the obese individuals exceeds that in any of the nonobese subjects.

The $V_{\max }$ for saturable oleic acid uptake and the rate constant $(k)$ for nonsaturable uptake were both highly

Table 1 Patient characteristics ${ }^{\mathrm{a}}$

\begin{tabular}{|c|c|c|c|c|c|c|c|c|c|}
\hline Group & (n) & Age $(y)$ & Weight (kg) & $B M I\left(k g / m^{2}\right)$ & Insulin (ng/ml) & Leptin $(n g / m l)$ & Glucose (mg/dl) & Cholesterol (mg/dl) & Triglycerides $(\mathrm{mg} / \mathrm{dl})$ \\
\hline \multicolumn{10}{|l|}{ Obese } \\
\hline Male & (5) & $49.0 \pm 10.7$ & $164 \pm 34$ & $56.4 \pm 14.4$ & $13.1 \pm 5.2$ & $18.6 \pm 8.6$ & $122 \pm 33$ & $174 \pm 40$ & $130 \pm 96$ \\
\hline Female & (5) & $44.4 \pm 3.6$ & $115 \pm 9$ & $43.2 \pm 1.8$ & $10.5 \pm 3.9$ & $24.5 \pm 5.2$ & $120 \pm 33$ & $265 \pm 23$ & $163 \pm 16$ \\
\hline Total & $(10)$ & $46.7 \pm 7.9$ & $139 \pm 35$ & $49.8 \pm 11.9$ & $11.8 \pm 4.5$ & $21.6 \pm 7.4$ & $121 \pm 31$ & $224 \pm 56$ & $146 \pm 67$ \\
\hline \multicolumn{10}{|l|}{ Nonobese } \\
\hline Male & (5) & $48.2 \pm 12.6$ & $78 \pm 7$ & $24.9 \pm 1.8$ & $8.2 \pm 4.6$ & $3.2 \pm 2.7$ & $66 \pm 10$ & $190 \pm 56$ & $142 \pm 19$ \\
\hline Female & (5) & $48.2 \pm 11.0$ & $69 \pm 12$ & $23.5 \pm 2.6$ & $4.9 \pm 2.4$ & $7.0 \pm 6.3$ & $77 \pm 14$ & $177 \pm 32$ & $129 \pm 44$ \\
\hline Total & $(10)$ & $48.2 \pm 11.2$ & $74 \pm 10$ & $24.2 \pm 2.3$ & $6.7 \pm 4.0$ & $4.9 \pm 4.8$ & $72 \pm 13$ & $184 \pm 43$ & $136 \pm 33$ \\
\hline
\end{tabular}

${ }^{\mathrm{a} A l l}$ values mean \pm s.d. 
Table 2 Kinetic parameters of adipocyte LCFA uptake ${ }^{a}$

\begin{tabular}{|c|c|c|c|c|c|c|}
\hline Group & $\begin{array}{c}V_{\max } \\
(\mathrm{pmol} / \mathrm{s} / 50000 \text { cells })\end{array}$ & $\begin{array}{l}\mathrm{K}_{\mathrm{m}} \\
(n M)\end{array}$ & $\begin{array}{c}\mathrm{k} \\
(\mathrm{ml} / \mathrm{s} / 50000 \text { cells })\end{array}$ & $\begin{array}{c}\text { Adipocyte } \\
\text { surface area }\left(\mu^{2} / \text { cell }\right)\end{array}$ & $\begin{array}{c}\mathrm{V}_{\max }{ }^{\prime}=\mathrm{V}_{\max } / \text { surface area } \\
(p m o l / s / 50000 \text { cells })\end{array}$ & $\begin{array}{c}\mathrm{k}^{\prime}=\mathrm{k} / \text { surface area } \\
\left(\mathrm{ml} \times 10^{-8} / \mathrm{s} / \mu^{2}\right)\end{array}$ \\
\hline \multicolumn{7}{|l|}{ Obese } \\
\hline Male & $24.2 \pm 5.9$ & $155 \pm 29$ & $0.016 \pm 0.0023$ & $44986 \pm 5597$ & $1.07 \pm 0.21$ & $0.71 \pm 0.05$ \\
\hline Female & $18.4 \pm 5.8$ & $163 \pm 116$ & $0.014 \pm 0.0004$ & $38030 \pm 1892$ & $0.97 \pm 0.31$ & $0.74 \pm 0.05$ \\
\hline Total & $21.3 \pm 6.3$ & $159 \pm 80$ & $0.015 \pm 0.0019$ & $41508 \pm 5381$ & $1.02 \pm 0.26$ & $0.73 \pm 0.05$ \\
\hline \multicolumn{7}{|l|}{ Nonobese } \\
\hline Male & $4.0 \pm 1.4$ & $98 \pm 45$ & $0.0063 \pm 0.0023$ & $16976 \pm 8496$ & $0.56 \pm 0.34$ & $0.85 \pm 0.35$ \\
\hline Female & $6.1 \pm 1.8$ & $125 \pm 46$ & $0.0069 \pm 0.0026$ & $16879 \pm 4871$ & $0.80 \pm 0.40$ & $0.88 \pm 0.499$ \\
\hline Total & $5.1 \pm 1.9$ & $111 \pm 45$ & $0.0066 \pm 0.0023$ & $16928 \pm 6529$ & $0.68 \pm 0.37$ & $0.87 \pm 0.41$ \\
\hline
\end{tabular}

${ }^{\mathrm{a}}$ All values mean \pm s.d.

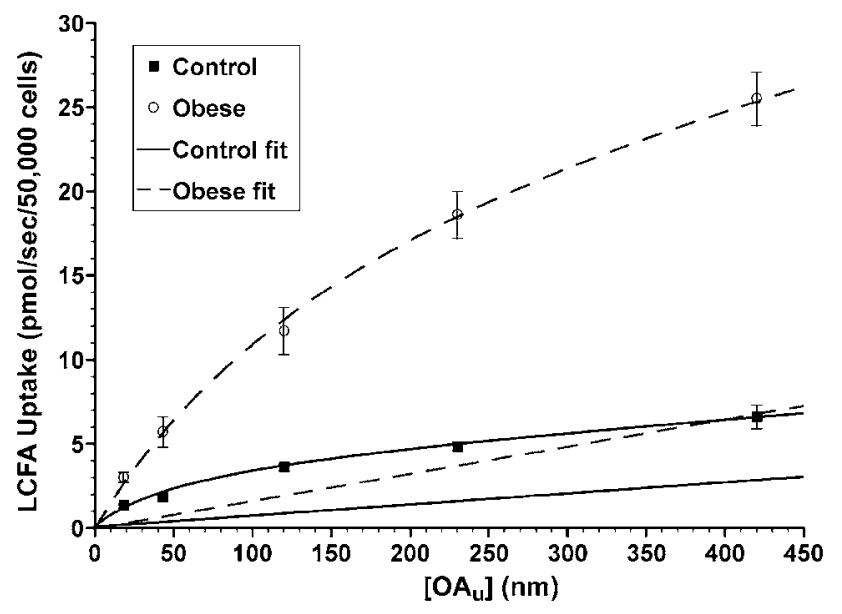

Figure 1 Representative studies of OA uptake by omental adipocytes isolated during bariatric surgery from an obese patient (BMI $80 \mathrm{~kg} / \mathrm{m}^{2}$ ), and from a nonobese patient (BMI $25 \mathrm{~kg} / \mathrm{m}^{2}$ ) during a laparoscopic cholecystectomy. Values are means \pm s.d. of triplicate determinations at five different $\left[\mathrm{OA}_{\mathrm{u}}\right]$ concentrations. Where no error bars are shown, their range was smaller than the data point symbol. Plotted curves were fitted by computer to the sum of a saturable and a non-saturable function of $\left[\mathrm{OA}_{\mathrm{u}}\right]$. Curves representing both total OA uptake and the computer-generated nonsaturable uptake component are shown for each study.

significantly increased in obese subjects compared with the values in nonobese subjects (Table $2 ; P<0.001$ ). As reported in multiple animal models of obesity, ${ }^{3,4}$ the 4.2 -fold increase in $V_{\max }$ was appreciably greater than the increase in adipocyte SA. While $K_{\mathrm{m}}$ is increased by a mean of $43 \%$ in obese patients, this was not significantly greater than that in the nonobese population in the present study $(P=0.09)$, due at least in part to the large variances in this parameter in both populations.

\section{Relationship of LCFA uptake to adipocyte size}

Both $V_{\max }$ and $k$ were highly correlated with adipocyte SA ( $r=0.87, P<0.001$ and $r=0.93, P<0.001$, respectively), raising the question of whether the increased LCFA uptake in these cells

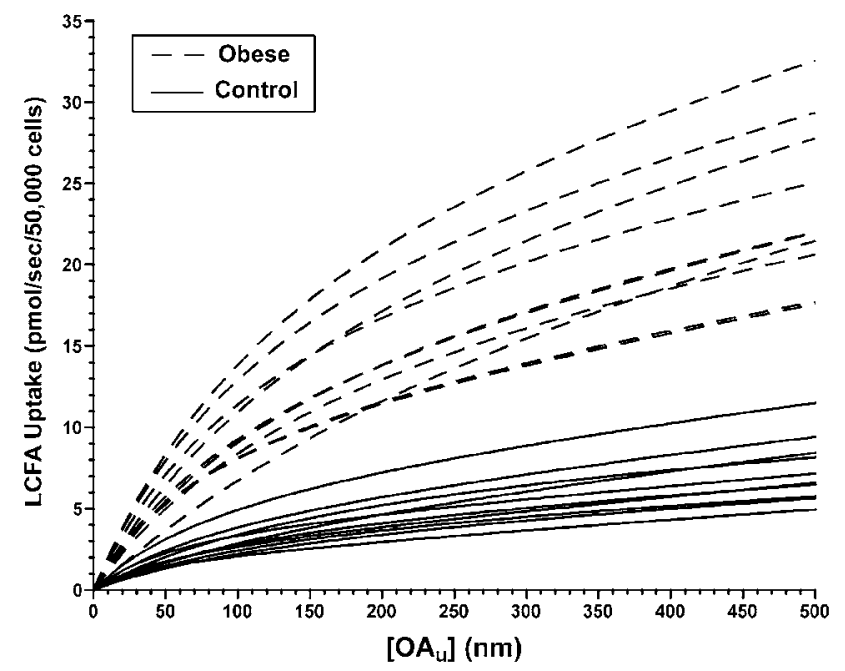

Figure 2 Computer fits to the OA uptake data in 10 obese (dashed lines) and 10 nonobese (solid lines) subjects. There is no overlap between the groups. Kinetic parameters calculated from these curves are presented in Table 2.

is simply a reflection of increased cell size. To address this issue, it is useful to express $V_{\max }$ and $k$ explicitly as functions of cell SA:

$$
V_{\max }(\mathrm{pmol} / \mathrm{s} / 50000 \text { cells })=V_{\max }{ }^{\prime}(\mathrm{pmol} / \mathrm{s} / \mathrm{SA}) \mathrm{SA} \text { and }
$$

$$
k(\mathrm{ml} / \mathrm{s} / 50000 \text { cells })=k^{\prime}(\mathrm{ml} / \mathrm{s} / \mathrm{SA}) \mathrm{SA}
$$

where the SA denoted here is that of 50000 cells. Based on the units in which $V_{\max }$ and SA are measured experimentally, the corresponding units for $V_{\text {max }}{ }^{\prime}$ are $\left(\mathrm{pmol} \times 10^{-8} / \mathrm{s} / \mu^{2}\right)$, and for $k^{\prime}$ are $\left(\mathrm{ml} \times 10^{-8} / \mathrm{s} / \mu^{2}\right)$ (Table 2). Equations (2) and (3) indicate that correlations between $V_{\max }$ and $k$, on the one hand, and SA, on the other, are to be expected and do not, in and of themselves, provide an answer to the question. However, $V_{\max }{ }^{\prime}$ was significantly increased in adipocytes from obese individuals compared with those from nonobese patients (Table $2, P<0.05$ ). For reasons presented in detail earlier, ${ }^{5}$ this increase in $V_{\max }{ }^{\prime}$ 
indicates that the overall increase in $V_{\max }$ and saturable LCFA uptake observed in obese adipocytes is not merely reflective of an increased cell size, but rather, indicates upregulation of a membrane transport system mediating LCFA uptake. By contrast, the value of $k^{\prime}$, while slightly greater in nonobese adipocytes, was not significantly different between adipocytes from obese and nonobese subjects (Table 2, $P>0.1$ ). Over the range of cell sizes encompassed by obese and nonobese adipocytes, both the magnitude and direction of the small difference observed are consistent with the small increases in the permeability of lipid bilayer membranes to amphipathic molecules that occur with decreases in the radius of curvature. ${ }^{1,2}$ Thus, $k^{\prime}$ reflects the permeability of adipocyte plasma membranes to LCFA per unit SA, and is largely independent of cell size. Accordingly, nonsaturable LCFA uptake at any given $\left[\mathrm{OA}_{\mathrm{u}}\right]$ can be approximated by

$$
\mathrm{UT}_{\mathrm{NS}}\left(\left[\mathrm{OA}_{\mathrm{u}}\right]\right) \cong k^{\prime} \mathrm{SA}\left[\mathrm{OA}_{\mathrm{u}}\right] \text {. }
$$

That nonsaturable uptake reflects the product of a permeability term $\left(k^{\prime}\right)$ and an area term is consistent with our hypothesis that $k$ is a measure of the rate of passive diffusion ('flip-flop') of LCFA into cells. ${ }^{1,2,23}$

\section{Correlations among measured variables}

$V_{\max }$ was highly significantly correlated with both body weight $(r=0.908)$ (Figure 3$)$ and BMI $(r=0.869)(P<0.01$ in each case). As expected, both plasma insulin and leptin concentrations were also correlated with BMI $(r=0.669$ and 0.635 , respectively) and body weight $(r=0.680$ and 0.640 , respectively) $(P<0.01$ in each instance). As a result, there were significant correlations between insulin $(r=0.662)$ and leptin $(r=0.754)$ concentrations and $V_{\max }(P<0.01)$.

\section{Discussion}

Obesity is widespread in the US, and carries with it profound health issues with enormous health care costs. ${ }^{24,25}$ It is a

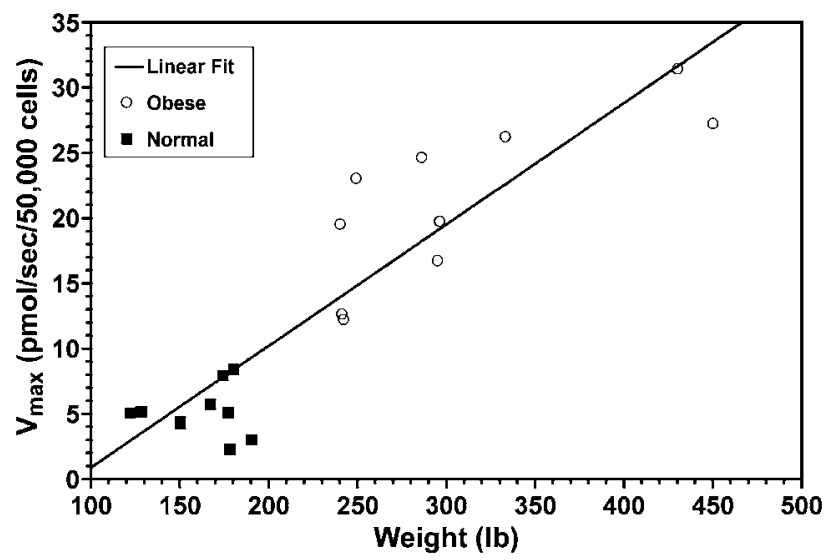

Figure 3 Relationship between body weight and the $V_{\max }$ for saturable LCFA uptake. The correlation coefficient $(r=0.908)$ is highly significant $(P<0.01)$. major risk factor for noninsulin-dependent diabetes mellitus (NIDDM), and is associated with excess morbidity and mortality from many causes, including cardiovascular disease, liver disease, and cancer. As summarized by Leibel et $a{ }^{26}{ }^{26}$ only three basic mechanisms or a combination thereof can lead to the development of obesity: (I) a relative increase in energy intake; (ii) a relative decrease in energy expenditure; and (iii) preferential partitioning of ingested calories to storage as fat. As the most energy-dense nutrient, changes in LCFA disposition may play a role in each of these mechanisms.

LCFA are major energy substrates, key components of cell membranes, precursors of important signaling molecules and other biologic mediators, and critical intracellular regulators of gene expression. Their entry into cells was long believed to occur by passive diffusion through the lipid bilayer of plasma membranes. However, recent work has clearly established that LCFA enter many cell types by both the facilitated, protein-mediated transport of LCFA anions and the passive diffusion ('flip-flop') of the uncharged, protonated fatty acid. ${ }^{1,2}$ Based on determination of the $t_{1 / 2} \mathrm{~S}$ for the movement of a fatty acid molecule across the plasma membranes of isolated rat adipocytes and hepatocytes, the facilitated process is at least 10-fold faster than that of passive flip-flop. ${ }^{2,23}$ Under basal physiologic conditions, more than $90 \%$ of LCFA uptake by hepatocytes, adipocytes, and cardiac myocytes occurs via the saturable, facilitated process. ${ }^{9,11,13,27,28}$

Altered LCFA disposition is typical of both obesity and NIDDM. ${ }^{29,30}$ Indeed, some believe that such changes are the primary disturbances in these conditions. ${ }^{31-34}$ Animal models have been very useful in studying this process. The discovery of leptin and the role of leptin deficiency in the $o b /$ $o b$ mouse in $1994^{35}$ opened the door to an explosion of information about the existence and roles of numerous hormones, as well as systemic and localized neuropeptides, involved in complex regulatory loops that modulate feeding behavior, energy expenditure, and various aspects of intermediary metabolism (reviewed in Friedman and Halaas ${ }^{36}$ ).

Our studies in the $f a / f a \mathrm{rat}^{3}$ and the $o b / o b, d b / d b$, fat, and tubby mouse models of genetically determined obesity ${ }^{4,5}$ as well as both rat and mouse models of dietary obesity ${ }^{4}$ found that the $V_{\max }$ for saturable LCFA uptake in adipocytes was appreciably upregulated in every instance. In virtually all of the models studied, saturable uptake per unit of SA $\left(V_{\max }{ }^{\prime}\right)$ was significantly increased in adipocytes from obese animals compared to appropriate controls (Figure 4), suggesting that the increase in saturable uptake resulted from upregulation of a facilitated membrane transport system. ${ }^{5}$ By contrast, the increase in $k$ in the absence of a significant increase in $k^{\prime}$ indicated that the increased nonsaturable uptake reflected passive diffusion across the increased SA of enlarged obese adipocytes. All of these observations have been confirmed in the present study in human omental adipocytes.

Several further observations in the animal model studies have not yet been confirmed in man. In particular, the 
SATURABLE LCFFA UPTAKE BY ADIPOCYTES IN OBESE MICE, RATS AND MAN

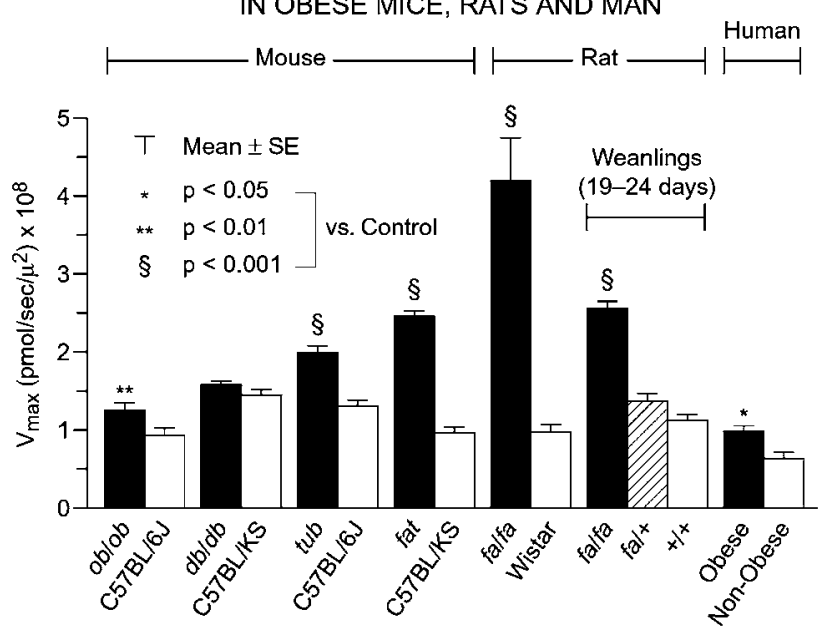

Figure 4 Comparison of $V_{\max }{ }^{\prime}\left(\mathrm{pmol} \times 10^{-8} / \mathrm{s} / \mu^{2}\right)$ in adipocytes from obese and nonobese subjects. Human data are from the current study. Data in obese mice and rats and appropriate control strains are replotted from Berk et al. ${ }^{3,4}$ Saturable LCFA uptake $/ \mu^{2}$ of adipocyte SA was increased in all groups. All differences were significant except in $d b / d b$ mice.

upregulation of saturable LCFA uptake was found to be tissue-specific, in that, in marked contrast to adipocytes, saturable LCFA uptake by hepatocytes and cardiac myocytes from obese animals was virtually unchanged from control values. ${ }^{2,3}$ We have not yet had an opportunity to study LCFA uptake kinetics in human liver or cardiac muscle. The increase in adipocyte LCFA uptake in weanling Zucker fatty $(\mathrm{fa} / \mathrm{fa})$ rat pups was found to precede by several days enlargement of adipocytes and weight gain, ${ }^{3}$ whereas the rapid downregulation of saturable LCFA uptake that results from leptin infusion in the $o b / o b$ mouse precedes reductions in food intake, increased locomotor activity, and weight loss. ${ }^{5}$ Again, it has not yet been possible to make analogous observations in man. Several lines of observation in animals have led us to speculate that insulin normally upregulates, and leptin downregulates, saturable LCFA in adipocytes. ${ }^{3-5}$ We consider that the significant correlation observed between plasma insulin levels and $V_{\max }$ in the current studies is consistent with the first of these speculations. The correlation between leptin levels and $V_{\max }$ may, by contrast, be a manifestation of leptin resistance.

Finally, alterations in saturable LCFA uptake in several rodent obesity models ${ }^{3-5}$ and in differentiating mouse 3T3L1 preadipocytes ${ }^{37,38}$ have been consistently associated with parallel changes in the expression, at both mRNA and protein levels, of putative LCFA transporters such as plasma membrane fatty acid binding protein $\left(\mathrm{FABP}_{\mathrm{pm}}\right)$ and fatty acid translocase (FAT/CD36). ${ }^{3-5}$ Indeed, the correlation between $V_{\max }$ and expression of mRNA levels for these transporters in some studies has achieved a value of $r=0.99 .^{3}$ As recently reviewed, ${ }^{6}$ the former of these has proven identical to the mitochondrial isoform of aspartate aminotransferase (mAs-
pAT). ${ }^{39-41}$ Nevertheless, its presence on adipocyte and hepatocyte plasma membranes has been firmly established by immunofluorescence, immunohistochemical, and immunoelectron microscopic techniques and by immunoprecipitation from highly purified plasma membrane preparations, ${ }^{6}$ while its function as a plasma membrane LCFA transporter was demonstrated in antibody inhibition, ${ }^{28}$ transfection, ${ }^{42}$ and microinjection ${ }^{43}$ experiments. Relative mRNA levels in these published studies were assayed principally by Northern hybridization analysis. In assaying the corresponding mRNA levels in the human adipocyte samples obtained in the present studies, we found frequent discrepancies between the results obtained by microarray, RT-PCR, and Northern hybridization assays. While we believe that these inconsistencies reflect a technical artefact, we are reluctant to express an opinion about mAspAT gene expression in human obesity pending full resolution of this unexpected problem, which in no way alters the interpretation of the oleic acid kinetic studies.

Based on observations to date in both rodents and man, it is our hypothesis that regulation of adipocyte LCFA uptake in response to imbalances between energy intake and energy expenditure from any cause is an important control point for body adiposity, both in terms of quantity and distribution (Figure 5). In particular, tissue selective upregulation of LCFA uptake by adipocytes would be expected to alter the partitioning of this energy dense nutrient, diverting it away from tissues where it is oxidized as fuel and into adipose tissue, where it is stored as fat. While the data obtained thus

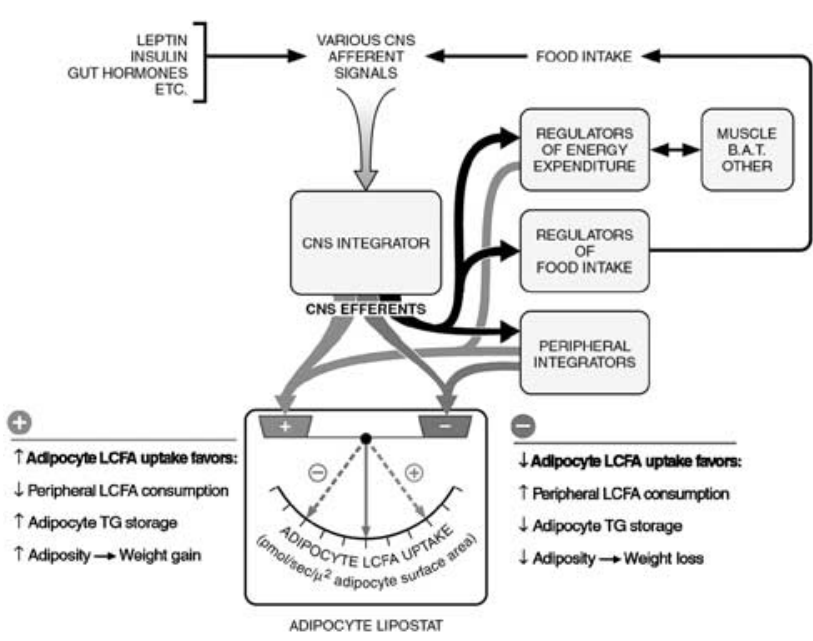

Figure 5 Regulation of adipocyte LCFA uptake controls body adiposity. Although the primary genetic defects in well-studied animal models of obesity are in the CNS ( $d b$ mouse, Zucker fatty rat) or in peripheral tissues (ob mouse), all such defects, as well as animal models of dietary obesity, result in selective upregulation of facilitated LCFA by adipocytes. This suggests that regulation of adipocyte LCFA uptake represents a final, common pathway for control of body adiposity resulting from a diversity of primary causes. The upregulation of adipocyte LCFA uptake observed in the present study suggests that a similar regulatory process applies to human adiposity. Reproduced from Clinics in Liver Disease ${ }^{44}$ with permission. 
far are fully consistent with this hypothesis, a full understanding of the role of fatty acid transport in the pathogenesis of obesity will require parallel studies of rates of lipolysis. These will be included in our future investigations.

Owing to the central role of LCFA in intermediary metabolism, a detailed understanding of cellular LCFA disposition, including their transmembrane transport, will yield important insights into the pathophysiology of obesity and the pathogenesis of obesity-related NIDDM and the entire spectrum of nonalcoholic fatty liver disease. ${ }^{44}$ Our efforts to clarify in fine detail the mechanisms involved in membrane transport of LCFA are directed at improving understanding of the underlying pathophysiology of an important group of diseases.

\section{Acknowledgements}

This work was supported by Grants DK-26438, DK-52401, and DK-66667 from the National Institutes of Health (NIDDK) and by the Mount Sinai Liver Disease Research Fund. We appreciate the advice of Dr Carol Bodian on biostatistical issues.

\section{References}

1 Berk PD, Stump DD. Mechanisms of cellular uptake of long chain free fatty acids. Mol Cell Biochem 1999; 192: 17-31.

2 Stump DD, Fan X, Berk PD. Oleic acid uptake and binding by rat adipocytes define dual pathways for cellular fatty acid uptake. J Lipid Res 2001; 42: 509-520.

3 Berk PD, Zhou SL, Kiang CL, Stump D, Bradbury M, Isola LM. Uptake of long chain free fatty acids is selectively up-regulated in adipocytes of Zucker rats with genetic obesity and non-insulindependent diabetes mellitus. J Biol Chem 1997; 272: 8830-8835.

4 Berk PD, Zhou S, Kiang C, Stump DD, Fan X, Bradbury MW. Selective up-regulation of fatty acid uptake by adipocytes characterizes both genetic and diet-induced obesity in rodents. J Biol Chem 1999; 274: 28626-28631.

5 Fan X, Bradbury MW, Berk PD. Leptin and insulin modulate nutrient partitioning and weight loss in ob/ob mice through regulation of long-chain fatty acid uptake by adipocytes. $J$ Nutr 2003; 133: 2707-2715.

6 Bradbury MW, Berk PD. Cellular uptake of long chain free fatty acids: the structure and function of plasma membrane fatty acid binding protein. Adv Mol Cell Biol 2004; 33: 47-81.

7 Abumrad NA, Perkins RC, Park JH, Park CR. Mechanism of long chain fatty acid permeation in the isolated adipocyte. J Biol Chem 1981; 256: 9183-9191.

8 Abumrad NA, Park JH, Park CR. Permeation of long-chain fatty acid into adipocytes. Kinetics, specificity, and evidence for involvement of a membrane protein. J Biol Chem 1984; 259: 8945-8953.

9 Schwieterman W, Sorrentino D, Potter BJ, Rand J, Kiang CL, Stump D, Berk PD. Uptake of oleate by isolated rat adipocytes is mediated by a $40-\mathrm{kDa}$ plasma membrane fatty acid binding protein closely related to that in liver and gut. Proc Natl Acad Sci USA 1988; 85: 359-363.

10 Di Girolamo M, Mendlinger S, Fertig JW. A simple method to determine fat cell size and number in four mammalian species. Am J Physiol 1971; 221: 850-858.

11 Sorrentino D, Robinson RB, Kiang CL, Berk PD. At physiologic albumin/oleate concentrations oleate uptake by isolated hepatocytes, cardiac myocytes, and adipocytes is a saturable function of the unbound oleate concentration. Uptake kinetics are consistent with the conventional theory. J Clin Invest 1989; 84: 1325-1333.

12 Sorrentino D, Berk PD. Free fatty acids, albumin and the sinusoidal plasma membrane: concepts, trends and controversies. In: Tavoloni N, Berk PD (eds). Hepatic transport and bile secretion. Raven Press: New York; 1993. pp 197-210.

13 Stremmel W, Berk PD. Hepatocellular influx of $\left[{ }^{14} \mathrm{C}\right]$ oleate reflects membrane transport rather than intracellular metabolism or binding. Proc Natl Acad Sci USA 1986; 83: 3086-3090.

14 Wosilait WD, Nagy P. A method of computing drug distribution in plasma using stepwise association constants: clofibrate acid as an illustrative example. Comput Programs Biomed 1976; 6: 142-148.

15 Spector AA, Fletcher JE, Ashbrook JD. Analysis of long-chain free fatty acid binding to bovine serum albumin by determination of stepwise equilibrium constants. Biochemistry 1971; 10: 3229-3232.

16 Bojesen IN, Bojesen E. Binding of arachidonate and oleate to bovine serum albumin. J Lipid Res 1994; 35: 770-778.

17 Richieri GV, Anel A, Kleinfeld AM. Interactions of longchain fatty acids and albumin: determination of free fatty acid levels using the fluorescent probe ADIFAB. Biochemistry 1993; 32: 7574-7580.

18 Rose $\mathrm{H}$, Conventz $\mathrm{M}$, Fischer $\mathrm{Y}$, Jungling E, Hennecke $\mathrm{T}$, Kammermeier $H$. Long-chain fatty acid-binding to albumin: re-evaluation with directly measured concentrations. Biochim Biophys Acta 1994; 1215: 321-326.

19 Berman M, Weiss MF. Users' manual for SAAM. US Government Printing Office: Washington DC; 1967.

20 \#\#SAAM II user guide. SAAM Institute: Seattle, WA; 1998.

21 Snedecor GW, Cochran WG. Statistical methods, 6th edn. Iowa State University Press: Ames, Iowa; 1967.

22 Zinder O, Shapiro B. Effect of cell size on epinephrine- and ACTHinduced fatty acid release from isolated fat cells. J Lipid Res 1971; 12: 91-95.

23 Stump DD, Nunes RM, Sorrentino D, Isola LM, Berk PD. Characteristics of oleate binding to liver plasma membranes and its uptake by isolated hepatocytes. I Hepatol 1992; 16: 304-315.

24 The Surgeon General's call to action to prevent and decrease overweight and obesity-2001. U.S. Department of Health and Human Services, Public Health Service Office of the Surgeon General. Government Printing Office: Washington DC; 2001.

25 Yanovski SZ, Yanovski JA. Obesity. $N$ Engl J Med 2002; 346: 591-602.

26 Leibel RL, Chung WK, Chua Jr SC. The molecular genetics of rodent single gene obesities. J Biol Chem 1997; 272: 31937-31940.

27 Sorrentino D, Stump D, Potter BJ, Robinson RB, White R, Kiang $\mathrm{CL}$, Berk PD. Oleate uptake by cardiac myocytes is carrier mediated and involves a $40-\mathrm{kDa}$ plasma membrane fatty acid binding protein similar to that in liver, adipose tissue, and gut. J Clin Invest 1988; 82: 928-935.

28 Stremmel W, Strohmeyer G, Berk PD. Hepatocellular uptake of oleate is energy dependent, sodium linked, and inhibited by an antibody to a hepatocyte plasma membrane fatty acid binding protein. Proc Natl Acad Sci USA 1986; 83: 3584-3588.

29 Groop LC, Saloranta C, Shank M, Bonadonna RC, Ferrannini E, DeFronzo RA. The role of free fatty acid metabolism in the pathogenesis of insulin resistance in obesity and noninsulindependent diabetes mellitus. J Clin Endocrinol Metab 1991; 72: 96-107.

30 Zakim D. Metabolism of glucose and fatty acids by the liver. In: Zakim D, Boyer TD (eds). Hepatology. Saunders: Philadelphia; 2002. pp 65-96.

31 Bjorntorp P. Fatty acids, hyperinsulinemia, and insulin resistance: which comes first? Curr Opin Lipidol 1994; 5: 166-174.

32 Kraegen EW, Cooney GJ, Ye JM, Thompson AL, Furler SM. The role of lipids in the pathogenesis of muscle insulin resistance and beta cell failure in type II diabetes and obesity. Exp Clin Endocrinol Diabetes 2001; 109 (Suppl 2): S189-S201. 
33 McGarry JD. What if Minkowski had been ageusic? An alternative angle on diabetes. Science 1992; 258: 766-770.

34 McGarry JD. Disordered metabolism in diabetes: have we underemphasized the fat component? J Cell Biochem 1994; 55 (Suppl): 29-38.

35 Zhang Y, Proenca R, Maffei M, Barone M, Leopold L, Friedman JM. Positional cloning of the mouse obese gene and its human homologue. Nature 1994; 372: 425-432.

36 Friedman JM, Halaas JL. Leptin and the regulation of body weight in mammals. Nature 1998; 395: 763-770.

37 Zhou SL, Stump D, Sorrentino D, Potter BJ, Berk PD. Adipocyte differentiation of 3T3-L1 cells involves augmented expression of a $43-\mathrm{kDa}$ plasma membrane fatty acid-binding protein. $J$ Biol Chem 1992; 267: 14456-14461.

38 Zhou SL, Stump D, Kiang CL, Isola LM, Berk PD. Mitochondrial aspartate aminotransferase expressed on the surface of 3T3-L1 adipocytes mediates saturable fatty acid uptake. Proc Soc Exp Biol Med 1995; 208: 263-270.

39 Berk PD, Wada H, Horio Y, Potter BJ, Sorrentino D, Zhou SL, Isola LM, Stump D, Kiang CL, Thung S. Plasma membrane fatty acid- binding protein and mitochondrial glutamic-oxaloacetic transaminase of rat liver are related. Proc Natl Acad Sci USA 1990; 87: 3484-3488.

40 Bradbury MW, Berk PD. Mitochondrial aspartate aminotransferase: direction of a single protein with two distinct functions to two subcellular sites does not require alternative splicing of the mRNA. Biochem J 2000; 345 (Part 3): 423-427.

41 Stump DD, Zhou SL, Berk PD. Comparison of plasma membrane FABP and mitochondrial isoform of aspartate aminotransferase from rat liver. Am J Physiol 1993; 265 (Part 1): G894-G902.

42 Isola LM, Zhou SL, Kiang CL, Stump DD, Bradbury MW, Berk PD. 3T3 fibroblasts transfected with a cDNA for mitochondrial aspartate aminotransferase express plasma membrane fatty acidbinding protein and saturable fatty acid uptake. Proc Natl Acad Sci USA 1995; 92: 9866-9870.

43 Zhou SL, Stump D, Isola L, Berk PD. Constitutive expression of a saturable transport system for non-esterified fatty acids in Xenopus laevis oocytes. Biochem J 1994; 297 (Part 2): 315-319.

44 Bradbury MW, Berk PD. Lipid metabolism in hepatic steatosis. Clin Liver Dis 2004; 8: 639-671. 